\title{
El concepto de verdad en las ciencias sociales: cosmos y logos
}

\author{
THE CONCEPT OF TRUTH IN SOCIAL SCIENCES: COSMOS AND LOGOS
}

Dr. Cristóbal Holzapfel (hcristob@gmail.com) Departamento de Filosofía, Universidad de Chile (Santiago, Chile)

\begin{abstract}
The article discusses the concept of truth in social sciences. Based upon Leibniz's sufficient reason principle, it is proposed three stadiums of the principle of sufficient reasons: ontological, epistemological and existential, which in turn allow three versions of the concept of truth in the social sciences.
\end{abstract}

Keywords: truth, Leibniz, sufficient reason, social sciences.

\section{Resumen}

El artículo discute el concepto de verdad en las ciencias sociales. Basado en el principio de razón suficiente de Leibniz, se proponen tres estadios del principio de razón suficiente: ontológico, epistemológico y existencial, los cuales permiten entender tres versiones del concepto de verdad en las ciencias sociales.

Palabras clave: verdad, Leibniz, razón suficiente, ciencias sociales.

\section{Introducción}

Si ya con Parménides tomamos conciencia de que no hay mayor enigma que el del ser, de que simplemente sea el ser, de que haya algo, se dé algo, de lo que en particular nos incita a tomar nuevamente conciencia el pensamiento de Martin Heidegger (2005), con Heráclito podríamos decir que trasunta todo su pensar la intuición de que el cosmos es íntegramente logos, vale decir, razón, aludiendo con ello a una razón cósmica universal, en lo que hay a su vez un anticipo de la concepción del ser humano como animal racional formulada posteriormente por Aristóteles, ya que, siempre todavía con Heráclito, podemos decir que distingue al ser humano, hace que el humano sea el que es, la posesión de ese logos en él, posesión que, en todo caso, supone nada más que una modesta participación del mencionado logos cósmico universal.

Si antes el enigma parmenídeo era el ser, cómo así que de pronto hay algo en términos absolutos, ahora con Heráclito el enigma es la constatación de que hay cosmos y logos y que además son algo uno; más precisamente el enigma es a propósito de cuál es el pliegue que une a ambos.

Ahora bien, si el cosmos en todas sus partes, sus recovecos, sus intersticios, en sus procesos, eventos, fenómenos, su acontecer incesante, su perpetuo cambio y movimiento, es logos, advertimos claramente en ello un anticipo de la formulación del principio de razón suficiente de Leibniz en el siglo XVII.

Teniendo en cuenta Heidegger de que el mencionado principio ya comienza a forjarse en la fragua del pensamiento griego desde sus mismos inicios (y agreguemos con Jenófanes de Colofón del siglo VI a.C.) el pensador de la Selva Negra habla de un período de incubación del principio mencionado de 2300 años (hasta Leibniz precisamente). 
La formulación del aquel principio reza así: "/.../ que nunca acontece algo sin una causa o siquiera una razón determinada, esto es, sin una cierta razón a priori, por qué existe algo y no más bien no existe y por qué existe más bien de éste que de ningún otro modo. Este importante principio vale para todos los acontecimientos, y no se deja aducir ninguna prueba contraria" (Leibniz 1986: \#44).

Esto quiere decir que no hay nada, en lo macrocósmico ni en lo microcósmico, ni siquiera la más mínima gota de agua de la lluvia, un electrón en su traslación alrededor del núcleo del átomo, cualquiera de las pelusas que flotan en el aire de la habitación, que se sustraiga ni por una sola milésima de segundo al principio, ya sea en lo que es o en su comportamiento. El universo en cualquier estado presente, pasado y futuro se comporta de acuerdo al principio, y aunque se suponga que hay hoyos negros en lo que se suspendería el espacio y tiempo, como también las leyes científicas, tal como conocemos todo eso, también debe haber necesariamente razones que tienen que ser para Leibniz al menos "siquiera suficientes" para que un hoyo negro sea como es y se comporte como se comporta.

Se sigue de ello que estamos ante un universo por decirlo íntegramente obediente al principio, el cosmos obedece en todo lo que es al logos. Si llueve es porque tiene que llover, si no llueve es porque no tiene que llover, si hay calor o si hay frío es porque tiene que haberlo. Todo obedece al principio leibniciano que da expresión al logos, que ya Heráclito concibiera.

Tanto más asombroso es entonces que haya ciertos entes en la inmensidad del ser que pueden desobedecer, elegir, y junto con ello ser libres, aunque esa sea una libertad siempre parcial y finita. Entre ellos, en particular el ente humano que somos nosotros, es cierto que tiene que alimentarse, dormir, descansar, hacer procesos metabólicos, morir, y demás, sin embargo muchas de esas determinaciones que caen sobre su ser, las puede postergar, hasta cierto punto incluso la muerte cuando esta llega no como el ladrón de la casa.

Y esa libertad es posible porque antes que cualquier determinación somos poder-ser, posibilidad, queriendo decir esto que nuestro propio ser es tal, y no al modo de la posibilidad de que llueva o no llueva, ya que esta última posibilidad en definitiva, y como ya veíamos, se somete al determinismo.

Pues bien, habría tres estadios del principio de razón suficiente: ontológico, epistemológico y existencial, los cuales serán abordados a continuación.

\section{Estadio ontológico del principio de razón suficiente}

El estadio ontológico da cuenta de cómo el logos está en el cosmos y lo determina íntegramente. El principium rationis ya está operando en las cosas mismas. Ratio tiene al menos dos acepciones: razón y fundamento. Si tomamos la última, podemos decir que en el estadio ontológico el fundamento está en la cosa, fundamentum in re. Nuestros ojos ven como tienen que ver con todas las operaciones del caso: contracción o dilatación del cristalino, lo mismo de la pupila, y otros. Las olas se forman, se desplazan y deshacen como tienen que hacerlo. El planeta gira como tiene que girar. Todo está regido por un secreto logos. Si relacionamos lo dicho con el poder, diríamos que el logos es el poder, y por lo mismo con justicia, podemos decir que es omnipotente.

Ahora bien, ¿qué es lo único que se presenta con ese aparente estatuto ontológico justificado de la omnipotencia? Pues nada más ni nada menos que el posible Dios. Ello se explica porque el propio logos, la suprema razón suficiente de todo ha sido concebido como Dios, como lo hace precisamente Leibniz. Ejemplar es en ello cuando se hace la pregunta que sería la más radical de todas: "¿Por qué es el ser que no más bien la nada?", respondiendo de inmediato: "Porque Dios es". Diríamos que éste es también un modo como se presenta el así llamado "dios de los filósofos", aunque bien sabemos que detrás de ese dios puramente conceptual, ese dios del pensamiento, suele estar el Dios de la fe, y tal es el caso de Leibniz. Y digamos además que también desde esta perspectiva se observa cómo se despliega aquí lo que Heidegger llamara 'ontoteología', queriendo enfatizar con ello que la ontología tradicional no ha sido simplemente eso -ontología- sino ontoteología. 
Y aquí llegamos al punto que más nos interesa relevar: en el estadio ontológico del logos, del principio de razón que antes de cualquier formulación ya opera en las cosas y las determina en lo que son y cómo se comportan, no puede haber sino verdad. Aquí el ser está en plena identidad con la verdad. El ser es la sempiterna verdad simplemente porque es.

Nos hemos olvidado de esta que evidentemente sería la Gran Verdad, incluso la Única Verdad propiamente tal, la Genuina Verdad. Cada uno en la medida en que simplemente es y existe, es parte de esa Verdad Inconmensurable.

Más allá de la identidad entre ser y verdad que se establece ya con Karl Jaspers, pero con mayor énfasis todavía, con Heidegger, me atrevería a extender el alcance de esta verdad a la verdad factual. Y atendiendo al rol que la verdad factual puede jugar la jurisprudencia es asaz decidora. En el caso del juicio que en el año 2014 se ha reabierto de la mujer que hace unos 5 años se habría suicidado en las afueras de la ciudad de Linares en Chile, suicidio que aparece ahora bastante extraño puesto que se habría inyectado 5 frascos de insulina más un poderoso calmante, ha entrado con mayor fuerza en sospecha un prestigioso abogado de la plaza, que habría sido su amante, siendo él un hombre casado, y ella se habría quedado embarazada. Al parecer, en razón de proteger su nombre y su prestigio habría intentado persuadirla de que realizara un aborto, a lo que ella se habría opuesto. Pues bien: ¿cuál es la verdad aquí?

La verdad corresponde pues a los hechos que efectivamente ocurrieron: tal vez el propio abogado asesinando a la mujer, o un sicario que contrató, o como se había sancionado hasta ahora: que fue un suicidio. Por más que se investigue, y ya después de 5 años, a lo mejor pasarán otros 5, y luego 10 o 30 años, y tal vez no sabremos nunca la verdad de los hechos. De momento esa verdad que estuvo tal vez en la conciencia de la mujer hasta que murió, sigue estando hoy en la conciencia del abogado, o de alguna tercera persona. Quizás transcurrido muchos años el propio abogado habrá muerto y con su muerte se habría llevado también la verdad de lo ocurrido. Aun así para los peritos forenses del futuro, con nuevos y más sofisticados métodos tecnológicos de peritaje, podrían encontrar alguna pista que les permita llegar a ciertas conclusiones y zanjar esta cuestión. Pero, de momento sabemos, como tendremos que tener siempre en cuenta, que la verdad está en lo que ocurrió y que el empeño de todas las mentes, de todas las racionalidades ha de ser dirigir su atención ante todo a eso, a lo que ocurrió, a los hechos.

Con todo, al ir más allá de la "verdad del ser", y hablar de la "verdad factual", ello trae consigo la limitación de restringir la verdad a un campo netamente empírico. Y respecto de lo que sea el cosmos puede valer también la verdad del mito.

\section{Estadio epistemológico del principio de razón suficiente}

Aquí ya se hace presente el ser humano, el sujeto cognoscente, el investigador, el que realiza la acción de "reddere rationem" (expresión del propio Leibniz) es decir, de volver a dar el fundamento, y agreguemos, a lo que de por sí lo tiene en ello mismo. En otras palabras, el óptico le vuelve a dar la razón o fundamento a la visión, y el audiólogo a la audición, como el biólogo al fenómeno de la vida. Y por cierto aquí entran también las humanidades y las ciencias sociales. El psicólogo le vuelve a dar el fundamento al trauma que presenta el paciente. El sociólogo le vuelve a dar el fundamento a la correlación que habría entre nivel cultural y delincuencia. El antropólogo le vuelve a dar el fundamento al sentido que tiene el don, el potlatch en las sociedades arcaicas. El historiador le vuelve a dar el fundamento al asesinato del Conde de Wallenstein en plena Guerra de los Treinta Años, relativamente a que supuestamente la orden habría venido del emperador de la Casa de los Habsburgo.

Ahora bien, en cualquiera de estos casos lo que hacemos es nada más que modestamente volver a dar el fundamento, puesto que el fundamento ya está en las cosas mismas. Si Crick y Watson alrededor de 1953 descubren la doble espiral cromozómica del ADN, le vuelven a dar el fundamento al fenómeno de la vida que de por sí tiene ese fundamento en la vida misma, y eso abarca hasta su supuesto origen en la Tierra alrededor de 4.000 millones de años atrás.

Y lo mismo respecto del potlatch, Marcel Mauss está simplemente volviendo a darle un fundamento en su obra Essay sur le don de 1925. 
Justamente por ello en este estadio puede haber verdad o error, aciertos y desaciertos. Parejamente aquí tiene lugar la acción no sólo de volver a dar el fundamento, sino también de quitarlo, así por ejemplo, en el paso del geocentrismo al heliocentrismo, luego al supuesto de que la vía láctea sería el centro del universo, y desde 1929 que habría un sistema sin centro. Las ciencias naturales y las sociales avanzan sobre base de estos "errores", que suelen verse en función de un cambio de paradigmas, de unas revoluciones científicas. Las ciencias naturales y más las ciencias sociales y las humanidades viven de la perpetua disputa que se da al modo de volver a dar y quitar el fundamento.

En el caso de las ciencias naturales, en particular de la física, las leyes que van descubriendo suponen que desde el estadio epistemológico se le va ganando terreno, aunque mínimamente, al logos cósmico universal. Ello patentiza también la diferencia entre filosofía y ciencia, en el sentido que en la primera se puede sostener un principio como el de razón suficiente y que abarca al universo íntegro del pasado, del presente y del futuro, en cambio las leyes científicas son el resultado cada vez del avance paso a paso del método científico. Algo similar ocurre también con otros principios que han emanado de la filosofía, como el de causalidad, de no-contradicción, de tercero excluido.

Es a su vez en el presente estadio epistemológico donde actúa la verdad en sentido aristotélico como adecuación del intelecto a la cosa, lo que a su vez constituye uno de los fundamentos del realismo. Y si bien, más allá del realismo aristotélico-tomista se plantea una nueva dirección en la adecuación, a saber con el giro copernicano de Kant, de las cosas al intelecto, la adecuación se mantiene.

Por cierto este sentido de la verdad como adecuación es para nosotros el habitual, el que permite que nos orientemos en la cotidianidad. Es verdad que la puerta está abierta o cerrada, y en eso, aunque irreflexivamente por lo general, me atengo a la adecuación, y tengamos presente que lo hacemos apoyándonos completamente en la adecuación aristotélica y no en la kantiana. En otras palabras, en los hechos somos más realistas que idealistas modernos. Si no hiciéramos, aunque sea irreflexivamente, la adecuación respecto de que en verdad la puerta está cerrada, no se me ocurriría abrirla y me daría un golpe de nariz contra ella.

Si bien lo dimensionamos, gran parte de nuestro mundo es fruto del presente estadio: calles, edificios, imprenta, electricidad, automóviles, aviones, telefonía, internet, y toda suerte de materias primas elaboradas, y otros. Y ciertamente que todo ello se puede ver a la par como fruto de la verdad como adecuación.

\section{Estadio existencial del principio de razón suficiente}

Aquí se trata no de que volvemos a dar el fundamento, sino simplemente de darlo, y darlo libremente. Es más, podría definirse la propia libertad como precisamente la libertad de dar el fundamento o quitarlo. Ello es sugerente porque es como si el logos cósmico universal no sólo se reflejara en el logos interno que nos permite organizar nuestras existencias, sino también en la libertad, más precisamente siendo una libertad que se rige por el logos, por las razones de mayor peso de elegir más bien esto que lo otro.

Lo que distingue al estadio existencial, en el que más cabalmente está alojado el ser humano, es que no hay un fundamento previo al cual remitirse, al menos no necesariamente. Si un alumno ingresa al Doctorado en Psicología de FACSO (Facultad de Ciencias Sociales) le da el fundamento a aquello y esperemos que en el transcurso de sus estudios doctorales no se lo quite. Ciertamente podría considerarse que hay toda una batería de fundamentos, de razones, incluso de sobra, para ingresar al mencionado Doctorado: al fin y al cabo pertenece a la Universidad de Chile. Y por supuesto que esos fundamentos, ciertamente previos, han de pesar en esa decisión. Nuestra conducta racional, equilibrada, sensata y sopesada normalmente es de esta índole, pero en rigor no por ello hay aquí un volver a dar el fundamento, más bien lo que hay es que en mi libre dar el fundamento tengo en consideración de que el mencionado doctorado vale, está bien estructurado, organizado, con una adecuada malla curricular, posee un cuerpo académico destacado, está acreditado, y otros, pero todo ello se justifica únicamente como algo que tenemos en consideración para que nuestra decisión de ingresar en el doctorado se justifique. 
Está claro además que en este estadio no hay en rigor propiamente un principio, sino simplemente razones suficientes posibles que se ponen en juego en nuestro actuar y andar por el mundo.

Sobre todo en este estadio sucede además que tiene plena justificación ir mucho más allá de una supuesta verdad de los hechos, la verdad factual.

Cuando Robert Musil (1992) escribe una de sus novelas de mujeres llamada "Tonka", parecer tener esto mismo en cuenta. Uno de los protagonistas es un joven ingeniero austríaco vienes que se enamora de Tonka, una mujer de una procedencia dudosa y en todo caso no perteneciente a la clase de la alta burguesía de la familia de él, razón por la cual la pareja constituida experimenta el rechazo de esa familia. Deciden entonces abandonar Austria y se van a vivir a Alemania, que sería más liberal, si bien la ciudad que escogen, München, es una de las cunas del catolicismo germano. Pasa un tiempo, y la pareja entra en crisis, interrumpiéndose entre ellos cualquier contacto sexual. De pronto ella se queda embarazada, y él sabe que él no sería el padre. Desesperado por esta situación acude al psiquiatra, y expone su situación: le cuenta los hechos al profesional, y éste le dice: "A ver, Ud. dice que Tonka es su esposa, que ella se quedó embarazada...entonces Ud. es el padre de la criatura". A lo que el ingeniero replica que no, que él sabe que él no es el padre. El psiquiatra vuelve a acometer y dice lo mismo que la vez anterior. Él responde otra vez que está seguro que él no es el padre. El psiquiatra dice lo mismo por tercera vez y exactamente como la vez primera. Sucede que entonces el ingeniero se queda pensando y responde: "Si, yo soy el padre".

Esto revela una verdad más profunda que la verdad de los hechos, se trata de una suerte de "verdad espiritual". Él asume la paternidad y la verdad empírica, basada únicamente en los hechos, ha quedado atrás (ver también la interpretación de Todd Konje 1987).

Claro está, frente a la verdad de los hechos puede haber verdades más profundas. Si se quiere, se puede ser padre sin ser padre, y a lo mejor aquel ingeniero será un muy buen papá por eso mismo.

\section{Bibliografía}

Heidegger, M. (2005) Ser y tiempo. Santiago: Editorial Universitaria.

Kontje, T. (1987) Motivating silence: the recreation of the "eternal feminine" in Robert Musil's "Tonka". Monatshefte 79(2): 161-171.

Leibniz, G. (1986) Theodizee. Frankfurt am Main: Insel

Musil, R. (1992) Tres Mujeres. Barcelona: Seix Barral.

Recibido el 15 May 2014

Aceptado el 23 Jun 2014 